\title{
Language and tools for networkers
}

Wielinga, H.E. (Eelke), Vrolijk, M. (Maarten)

Wageningen University and Research, The Netherlands

April 2008

\begin{abstract}
The network society has a major impact on knowledge systems, also in agricultural and rural development. It has changed relationships between actors such as farmers, extension workers, researchers, policy makers, businessmen and consumers. These changes require different language, concepts and tools as compared to the time that it was thought that science led the way, and new findings had to be disseminated to target groups. In this paper we argue that also the language of the market, talking about clients and knowledge producers, demand driven systems and calculable results is insufficient to describe what actually happens in innovative farmers networks or to guide knowledge workers in what to do for speeding up such processes.
\end{abstract}

The paper is based on experiences from a large scale experiment in the Netherlands: the "Networks in Animal Husbandry" programme (2004-2007). Yearly some 50 networks of entrepreneurs in animal husbandry have been assisted by 25 - 35 knowledge workers (mostly researchers from Wageningen University and Research). The basic idea was asking farmers to come up with innovative ideas that could help the sector further on the track of sustainable development, and then to assist them with scientific expertise. The facilitators were embedded in a learning community and they were provided with language, tools and methods that grew along the way. After three rounds with in total 120 networks and many meetings for joint reflection with the facilitators a huge amount of experiences has been registered. Their work required a new generation of tools: as 'free actors' they had to learn how to navigate in unknown areas, recognise at any moment what was at stake and intervene appropriately. The programme did not start with a theory or approach, but with an ambition to bridge the gap between research and farmers in a new manner. It ended up with the "FAN approach": Free Actors in Networks".

The concept of 'living networks' and the ecological view on knowledge, as explained in earlier IFSA conferences (Wielinga, IFSA 2004, 2006), were adopted in the programme as theoretical framework. In this paper we we describe the major outcomes of the experiment, the lessons learned regarding language and tools for knowledge workers working with networks, and new questions that have arisen.

\section{The experiment: networks in animal husbandry}

\section{Basic features}

In 2003 awareness raised amongst researchers and policy makers that for a more sustainable animal husbandry it would be necessary to stimulate cooperation between many actors who would have to engage into a process of knowledge co-creation. Therefore the gap between research, farmers and other actors must be bridged. This ambition was the starting point of the network programme, financed by the Dutch Ministry of Agriculture, Nature management and Food Quality, and carried out by Wageningen University and Research.

The main elements of the programme were the following:

- animal husbandry networks expressed their ideas for innovation;

- the programme provided facilitation with expertise and communication activities;

- the knowledge workers were embedded in a structure for reflection and methodological support.

The FAN approach required new competences for knowledge workers. Also farmers in networks had to adjust to a different role than they were used to. The network programme arranged continuously activities for network members and facilitators to be aware and to respect their new roles, to develop a common language, to focus the network goals and to stimulate the learning process in and around the networks; all critical elements for successful cooperation. The Free Actors (in most cases knowledge workers from Wageningen University and Research) facilitated the networks in such a way that after one year (the standard period for facilitating) the network members were capable of organizing the Free Actor role on their one. Facilitating a large number of networks with very different strategic goals has led to a wide variety of experiments. This variety made it possible to develop and to practice new 
language and new tools for networkers. This development was accelerated by a tailor made monitoring and evaluation approach.

Communication about the process and network results was also a basic element of the network programme. When you want to cooperate to reach targets sooner or more easily, it is necessary that other actors are aware of this. So they should be informed regularly. Therefore all networks communicated frequently, for instance through the weekly E-newsletter of the network programme. The number of subscribers to this "Attention Mail" rose quickly over 6000 . There are many examples during the last three years that this led to new actors joining a network, to exploring new expertise or to link with gatekeepers at the right moment.

\section{Results}

The networks have led to a wide variety of results. We summarise only a selection of examples, arranged along different types of output:

- Developing techniques and practices: e.g. a breeding programme for self-moulting sheep, less demanding in maintenance; a 'claw check' for sows in group housing in pig husbandry; a tool for measuring parasites in poultry housing; a prototype of a mobile milking robot, making it more easy for farmers to keep their cattle in the pasture.

- Opening up new markets and products: e.g. a brand for chicken meat of high quality and produced in an animal friendly way; a marketing chain for horse milk as quality food supplement; energy supply by biogas; biofuel from grass.

- Developing tools for exchange of experiences: e.g. a handbook for entrepreneurs in pig husbandry; an internet tool for monitoring the use of labour in dairy farms; a database for toppers and bloopers in animal husbandry; a tool for collegial consultation by multi-point video conferencing; an Early Warning System for recognising rare but hazardous diseases in pigs.

- Scaling up efforts: A network, discovering there were no easy answers to a parasite problem in poultry, convinced the sector organisation and the Ministry of Agriculture of the magnitude of the problem, resulting in a much larger fund for research; inspired by the tool for recognising vector diseases in pigs, the sector organisation for poultry production now invests in the development for a similar tool for chicken. In another example, the "Caring Dairy" network of 11 farmers developed new practices for producing milk for a special brand of ice cream, combining high quality with animal welfare and social responsibility. This concept has now been taken over by a dairy cooperative specialising in cheese, and is to be implemented by its 550 members. The researcher who facilitated this network has left his job at WUR to become project leader in the cooperative.

- Developing new forms of cooperation: Entrepreneurs with biogas production have formed an association to defend their interests; a network of dairy farmers works on merging their farms to one big enterprise, allowing for task division, specialisation and advantages of scale; two other networks seek private investors who are willing to share responsibility for the landscape; one network formed a cooperative that bought 200 hectares of agricultural land in order to transform it into new nature in interaction with civilians and others.

- Stimulating dialogue: A number of networks opened up dialogue with organisations managing nature reserve areas, promoting farming with nature; networks for animal friendly housing systems for dairy cows and also for rabbits involved animal welfare organisations in their search for improvements.

- Influencing rules and regulations: The rules for preventing specific disease in sheep did not allow for a proper breeding programme for self-moulting sheep. The network managed to convince policy makers to change the interpretation of the rules, allowing for improvement programmes. In another case, the newly formed association of biogas producers listed specific problems and possible solutions for the introduction of biodigesters. This document has considerable impact on government officials at both local and national level.

Not all networks were successful. Sometimes ambitions appeared to be not realistic, or different interests could not be reconciled. In each of the three phases two to four networks stopped untimely because energy to continue was lacking for various reasons. Energy appeared to be a crucial component, or, as one facilitator being interviewed at the end of the programme stated it: "If there is energy, everything is possible".

With 120 networks the list could easily be made much longer. What is shown here indicates that the work of the facilitators included much more than supplying knowledge on demand. With a technical issue as a point of entry, they were involved in processes of knowledge co-creation, involving not only farmers with initiatives but also others like experts, policy makers, representatives, etc.. 


\section{Tools for networkers}

\section{What is so special about networks?}

Networks cannot be managed as organisations. Since the nineties we have been taught that any operation should start with a mission. This mission is to be operationalised into S.M.A.R.T. formulated targets (Specific, Measurable, Applicable, Realistic and Time bound). Subsequently we should choose the appropriate instruments, preferably with evidence based effectiveness. Then we start thinking about competences, where to get people with the required qualifications or how to train them for reaching the desired level. Finally we have to bind them to performance indicators in order to make them do what has been planned for.

It sounds rational, but it does not work. At least not for networks. Suppose someone has an initiative. For creating movement he or she will need others to join. But they have their ambitions too. If they become inspired, this means that they see possibilities for working on their own ambitions while supporting the initiative. But the initiative and all these ambitions will not be exactly the same. While mobilising supporters, the initiator will have to negotiate, and the goal of the network of people who decide to take action might differ from the one he or she started with. While working together, the network participants will encounter unexpected situations and discover things, which might lead to a reconsideration of the goal. Furthermore, if the process is healthy, mutual trust will grow, which usually leads to a higher level of ambitions within the network. So, targets become more clear and realistic throughout the process, and the network ends up with a mission that is really shared.

In the FAN approach we have put the schedule upside down (figure 1). Instead of starting with a mission and targets and ending up with instructing people, we start with people, and look for their ambitions for which they feel energy. Then we try to connect these people so that they can share this energy for creating movement. The targets will become clear over time. A shared mission is not the start of a good process, but the result of it.

Once having clear and shared targets, it is still useful to plan for activities, to choose instruments, and to work on competences. And nothing will start moving without at least someone with an ambition for which he or she takes the initiative. If there is energy in it, it will attract others. The principle difference is, however, that the trace to be followed cannot be completely foreseen. As long as managers have competences to make people do what is expected from them, they can control the process (or at least have the illusion they can). Networkers depend from voluntary contributions. This requires a different approach. They must

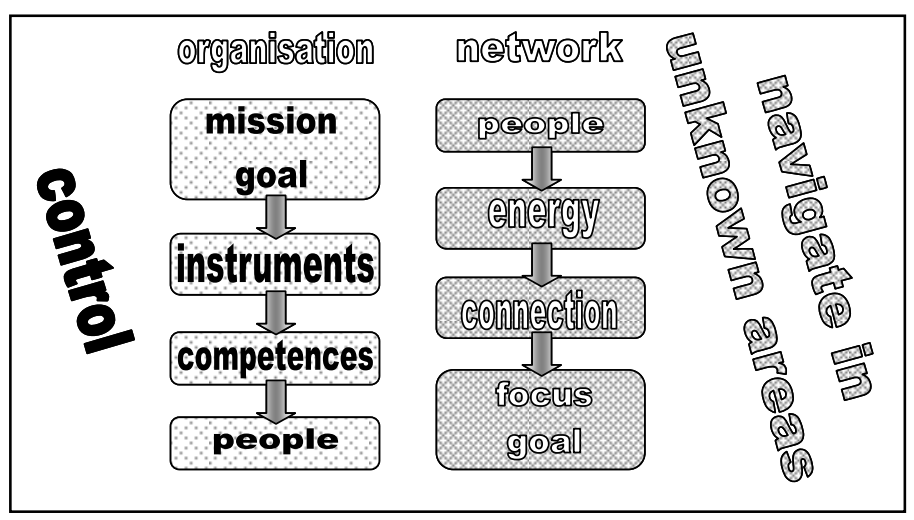

Figure 1: Different organisational principles for organisations and networks navigate in unknown areas, recognise what is at stake, and act accordingly for maintaining the energy level in the network. Where fixed targets are no longer reliable landmarks for navigation, energy and connection can serve as indicators for being on track.

\section{Tools for navigating in unknown areas}

These indicators require a different generation of tools. During the experiment several tools have been introduced, providing language for networkers for assessing their situation and choosing appropriate interventions. Within the scope of this paper, they can only be mentioned briefly:

The Network Analysis distinguishes positions of involvement: partners, links, suppliers and users. This tool helps to assess the viability of the network, and gives direction for connections to work on (Poorthuis 2006). Key questions are: Which actors are involved? How can we connect with them? Which positions do they take? Which key players are lacking? Is this a network we can build on? 
The Spiral of Innovations distinguishes stages of an innovation process: initial idea, inspiration, planning, development, implementation, dissemination and embedding. In each stage the role of knowledge differs, e.g. from finding knowledge as the best way in the development stage to knowledge as a weapon in the implementation phase when the environment must give way for change. Each stage requires connections with different actors, e.g. supporters in the inspiration stage, managers and financers in the planning stage and experts in the development stage. Key questions are: How far has the idea been developed? What is the next step to be taken? What type of knowledge is required? Which actors are to be involved? This tool will be explained further later on in this paper.

The Triangle for Change distinguishes change agents, gatekeepers and survivors. Only if change agents have generated sufficient energy, they can effectively negotiate with gatekeepers. It is a waste of energy to start with convincing survivors: they will only move along if risks for their positions have been reduced to a minimum. (Wielinga 2001, 2004). Key questions are: Who is generating energy for change? In what order should relevant actors be approached? What is proper timing?

The Circle of Coherence distinguishes patterns of interaction. In healthy interaction there is 'vital space' where people build up trust, curiosity and commitment. Each pattern can turn into an unhealthy version, leading to a loss of motivation and coherence. The tool suggests for each pattern a 'warm' and a 'cold' intervention in order to restore connection and vital space. Warm roles, like the inspirator, negotiator or joker, work through communication. Cold roles, like the regulator or the strategist, work through positioning. (Wielinga 2001, 2004). Key questions are: How healthy is the interaction? What connection is the limiting factor? What intervention for improving interaction fits best to the actual pattern?

\section{Monitoring and evaluation}

If fixed targets are not the only point of reference anymore, monitoring and evaluation requires different tools as well. It soon became clear that collecting statistical data about the progress had little use. Instead, a method for reflexive evaluation was introduced, combining the "time line method" with "learning histories" (Kleiner, A., Roth, G. 1997). Following the time line method, the network participants are asked to list all remarkable moments in the process since the start, both positive and negative, and to place them on a line indicating the calendar. Also the "penny-drop" moments are indicated. This exercise, taking only a limited amount of time, arouses vivid and useful discussions and usually stimulates the network to take responsibility for next steps. Facilitators continue by using the results for their learning histories, adding their analysis to the critical incidents that appeared from the time line. For their analysis they made use of the tools as mentioned above.

\section{Intuition}

Some networkers seem to be born for their job. They have the feel for what is going on and do what is needed. If you ask them afterwards what they did and why they did it, they probably cannot tell you. Often they do not even realise they did something important. In the experiment it took quite some effort with the network facilitators to reconstruct what interventions they made and how this influenced the process. They have a well developed intuition which they trust. The tools that were mentioned above have not been designed to replace this intuition by evidence based methods. Instead, they served to sharpen this intuition further, by providing language to distinguish different situations, and reflecting on interventions and their effects. Reflective meetings in small groups of 5 to 7 facilitators became an important element of the experiment.

The scientific justification for the importance of intuition can be found in the theory of living networks (Wielinga 2001, 2006). This theory postulates networks of people as living entities that can be healthy or sick. A healthy network generates energy: people find it rewarding to be part of it, they are willing to make efforts and to attune their input to what the network requires. This makes the reward higher, and their willingness will further increase. At times networks can absorb energy as well. Then the reward does not match the efforts anymore. The willingness of people to give their input and to attune to others decreases, making the network less attractive again. These are self propelling processes. The difference between healthy and unhealthy is connection. Just like any living organism or ecosystem in nature, networks can grow towards more task division, specialisation and complexity as long as the components remain interconnected. 
The steering mechanisms for autonomous and healthy growth in living organisms are in-built. In human networks this translates into people who feel by intuition what needs to be done to keep the network healthy. Rational decision making is a part of it, gaining importance in only the very last stage of the evolution. Although the antenna for what is required is in-built, many things can occur during a human lifetime that make it rather selective. The repertoire of possible responses to certain situations might be limited as well. "For someone with only a hammer everything looks like a nail", the proverb says. That is why we focussed on tools to recognise network processes and to increase the repertoire of interventions to choose from. The comparison with martial arts Eastern style is interesting. If a fighter must think about his response during a fight he probably is too late. But he has to train extensively to have a wide range of possible responses at his disposal in the split second when he needs to do the right thing.

\section{Knowledge in four varieties}

\section{Dominant narratives}

In earlier contributions to IFSA conferences a distinction was made between different narratives or rationalities, governing decision making in agricultural knowledge systems: the instrumental, the strategic, the communicative and the ecological rationality (Wielinga 2004, 2006). Each rationality leads to a distinguished concept of knowledge, approach for applying knowledge, and justification for action. Interestingly, the experiment pointed out that all four approaches could be recognised simultaneously. They appeared to be linked to different stages of development of an initiative, from primary idea to embedding of new practices in the knowledge infrastructure. Instead of rationalities or paradigms, we might better speak of different aspects of knowledge that appear on stage, depending on the circumstances. We will illustrate the four varieties of knowledge with examples from the experiment. For doing so, we make use of the "Spiral of Innovations", one of the tools that were developed during the experiment (figure 1).

\section{The Spiral of Innovations}

The initial idea: This first stage is usually not planned for. Someone might walk around with a vague ambition or a problem and suddenly get an idea. The first spark might also come from an encounter, a coincidence, something unexpected. Some people are always looking for new things. The chance for getting ideas increases by contacts outside of the wellknown circle, and by looking outside-in instead of inside-out.

The inspiration stage: Once he starts to talk about his idea with others, the inspiration stage has began. People with similar ambitions see opportunities by joining forces. Exchanging ideas about change generates energy. An informal network of change agents is being formed.

The planning stage: Sooner or later this network will feel the need for action. This is where the planning stage starts. Resources must be mobilised. Maybe the network has to connect with financers, or with managers who should allow for experiments. At the end of the planning stage the network participants have agreed on what to do and who should do it.

The development stage: Then the search-and-learn process gets at steam. The network will look for expertise, investigate different possibilities and participants might experiment with various practices. This is usually a stage with ups and downs. Sometimes the network appears to be on a dead end track and has do return to the planning stage or even the inspiration stage. But discoveries that open up new perspectives give a lot of satisfaction.

The implementation stage: Knowing how to do something better is one thing, getting it implemented is another. Most often there are other actors who have to move as well, for giving a new practice a chance. Within a fixed structure changes are not always welcome. This is a stage of negotiations and strategy.

The dissemination stage: If others start to copy the new practice, we can speak of the dissemination stage. This can be an autonomous process. It can also be actively promoted. Sometimes a network has an interest in spreading the practice, for example when application by many reduces risks like in animal diseases. In other cases the network will loose its competitive advantage if others copy the 
innovation too early. If so, another actor should take up responsibility for dissemination, and compensate the network for its investment in the development. If a new practice becomes widely accepted, it has become an innovation.

The embedding stage: In the embedding stage the structure adapts to the new practice. This can take form in regular connections, changed patterns, altered task divisions, contracts, or even reorganisations, etcetera. Thus, the innovation becomes part of regular practice.

The stages are represented in a spiral, indicating that innovation usually is not a linear process. Sometimes stages have to be repeated, and several stages can be at stake simultaneously. The distinction between these stages is useful for setting priorities for action. It leads to different answers on questions like: "Whom to connect with at this stage?", "What should be done first?" and "What aspect of knowledge should get attention?". With this distinction we will now illustrate four varieties of knowledge, each of them having their specific value and limitations (figure 2).

\section{Uncontested truth}

If knowledge is scientifically validated and uncontested amongst stakeholders, it can serve as a solid base for rational decision making. This aspect of knowledge is often what actors are looking for at the stage of development. Is it possible to obtain objective information that can prove that one practice is better than another? For a long period it was seen as the primary task of science to produce this type of knowledge, and to a large extend it still is. If such knowledge is available it can help a lot. Example: A network of poultry farmers wanted to address a problem with chicken mite. This parasite is hard to control with legal means. Just because

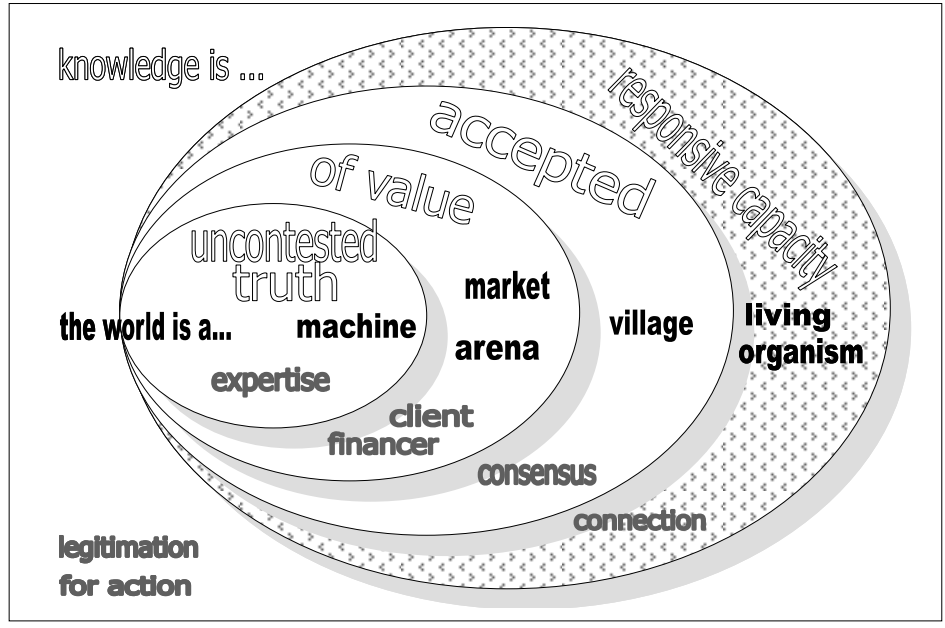

Figure 2: Four narratives about knowledge and legitimating action of this most farmers rather deny having problems. It was hard for the network to get support for their search. Then it developed a simple and cheap tool to detect the level of contamination in the chicken pen: a small tube with a stick inside leaving just enough space for the parasites to hide in daytime, as they usually do. The level of contamination can be observed when the little stick is taken out. When farmers tested it in their farm, the results were quite shocking and could no longer be ignored. The support for the network increased substantially.

Unfortunately such uncontested knowledge often is not available, at least not in the form stakeholders need it. In the case of the chicken mite, the network acquired an indication of the magnitude of the problem, but solutions appeared to be lacking, also after an investigation among international experts. In other cases there are competing theories leading to a different interpretation of data and different answers. When problems are getting more complex and stakes of interest are high, it becomes hard to find knowledge that is beyond suspicion. A third limitation can be that research based knowledge is context bound: many types of research require to limit the number of variables for investigation in order to draw hard conclusions. The relevance for reality in all its complexity might then be questioned. And if uncontested knowledge is obtained under certain circumstances, they might loose their relevance when these circumstances change. Such knowledge can become a 'blinding insight' for people who, under all circumstances, keep on believing what science once revealed.

\section{Knowledge of value}

Knowledge can have value for one actor, also when others disagree. This actor gives value to this knowledge when he finds it trustworthy and if it serves his interests. Trustworthiness depends on verifiability of the source and eventually the position of this source in a conflict of interests. 'Knowledge of value' fits well in the knowledge market where knowledge has become a product for sale. It can also be used as a weapon when competing with others for acquiring a better position. This aspect of knowledge often plays a role at the planning stage, when the network tries to create space for development. For getting approval, the arguments should fit into the line of thinking of the decision makers. Managers and policy makers often cannot wait before they dispose of uncontested knowledge 
for rational decision making. Many other factors play a role as well that affect the value they give to certain knowledge.

The same is true at the implementation stage when positions of other actors are affected. In one network, for example, poultry farmers had developed a mobile poultry pen, giving the chicken more roaming space that was also more fresh and clean than in usual extensive systems because these pens could be displaced regularly. However, this new concept did not fit into the existing environmental rules of the municipality. So, the municipal officers took it as one traditional fixed stable for the entire area where the mobile pens could be placed, which was not allowed at this spot. The assistance of the facilitator was not required for working out the concept: the farmers knew already how to do it. Instead, he was asked to deliver scientific arguments that could overrule the policy makers. They hoped for uncontested knowledge that could convince them, but in fact they wanted to use this knowledge as a weapon for acquiring space for their new concept.

\section{Accepted knowledge}

Knowledge can be the result of negotiation of a learning process. Such knowledge serves as a basis for agreements and concerted action. This is the kind of knowledge that is aimed for in interactive and participatory processes, where actors gradually learn about the interests of each other and what really is at stake. Apart from explicit knowledge from experts, also the images and experiences of individual actors play an important role in such processes. This fits well into the constructionist view, taking knowledge as an individual construct of reality. Shared knowledge is a result of interaction.

This aspect of knowledge played the key role in the networks throughout the programme. Sometimes, farmers had different expectations, however. Within their mindset of knowledge transfer, they thought that the expert-facilitator would have the answer to their questions or at least know where to find it. But most of the times such ready made answers were simply not available, and they had to engage into a search and learn process themselves. Then they would usually discover that it was much more satisfactory to work out appropriate answers themselves, being assisted by experts bringing in their parts of the jig saw puzzle. This process is referred to in literature as the co-creation of knowledge (following Nonaka and Takeuchi 1995).

In one example, a network of pig raisers aimed at lowering the costs for technical advice. The initiating farmers invited not only colleagues but also advisory services to join the network. These organisations appeared to be eager to join and sent advisors as well as managers. The first dialogue resulted in an agreement on changing the objective: to improve the effectiveness of technical advice, for getting more value for money. Then participants tried to link costs to effects per piglet, only to discover that everyone used different criteria and calculation methods. When this effort appeared to be hopeless, the network concentrated on two other tracks. One was to make recommendations for farmer and advisor to be more efficient, making use of the experiences of farmers which so far rarely had been done. The other track was on speeding up legal procedures for obtaining licences, which take quite some time from advisors. For this track also policy makers were invited. Sharing experiences did not only lead to useful recommendations for farmers and advisors, but also for government officers treating licence requests. The example shows how interaction leads to knowledge that is acceptable for stakeholders.

When other stakeholders have to give way for experiments of new practices, as is at stake at the stage of planning and implementation, using knowledge of value or as a weapon is one option, but accepted knowledge is to prefer in such cases. Therefore, interaction should be stimulated between the network and the stakeholders, if possible long before crucial decisions are to be made.

\section{Knowledge as responsive capacity}

Ultimately it was hoped for that the networks would not only be able to realise one idea or tackle one problem, but strengthen its capacity to respond to new situations. This is referred to as the responsive capacity of the system. Although it is hard to measure, it was observed that many networks grew in their capacity to manage itself, evolving from a collection of individuals joining efforts for one purpose to a network that knows how to solve problems and where to get support.

In this responsive capacity there is more knowledge involved than the explicit knowledge from experts or accepted knowledge that emerges from interaction. Also patterns, knowing how to mobilise people, agency, governance and the coherence of networks are playing a role. There are good reasons to 
include this entire complex of factors that influence responsive capacity into the concept of knowledge, as Maturana and Varela did in their Santiago theory (Maturana, Varela 1987). They investigated the biological function of knowledge, and concluded that all forms of life can exist through a 'cognitive cycle', enabling an organism to perceive signals, to give meaning to it and to generate a response. This mechanism enables organisms to connected to each other and maintain feed back mechanisms that keep the system healthy. The Santiago theory postulates that the function of knowledge in human systems is social coordination, which includes much more than only explicit knowledge. They define knowledge as "effective action in the domain of existence" (see also Capra 1996, Röling 1998).

This wide view on knowledge enables us to link other aspects as mentioned earlier to the quality of the network or the system in which this network has a function. The system is healthy as long as all essential elements are interconnected. Just like ecosystems, healthy living systems can grow towards more task division and specialisation as long as the coupling mechanisms grow along with the complexity. This evolutionary process generates energy, as could clearly be observed in the networks in the programme. With reference to the evolutionary process in ecosystems and the biological function of knowledge, we speak of an ecological view on knowledge (Wielinga 2004, 2006).

This view has important implications for the justification of knowledge interventions. The aspect of uncontested knowledge gives high value to science, and justifies action as the evidence based best way. The aspect of knowledge with value or knowledge as a weapon justifies action by the interests it is supposed to serve. The aspect of accepted knowledge justifies action by consensus among the stakeholders. For knowledge as responsive capacity the quality of essential connections is the prime focus. Interventions are justified if they improve the quality of these connections, that contribute to an innovative climate where the thresholds for taking initiatives is low.

\section{Conclusions}

\section{The FAN approach}

After the programme period of effectively 3,5 years we observe that many people involved, farmers, other stakeholders, facilitators and policy makers, are enthusiastic about the approach that emerged. Although it is not easy to obtain hard evidence, at least we can conclude that the FAN approach offers interesting perspectives for stimulating innovation at farmers level, and bridging the gap between farmers and research. At this stage, the approach cannot yet claim to be evidence based, but at least it is based on substantial experience. Features of the FAN approach that we see as crucial are the following:

- In the FAN approach farmers initiatives are the starting point for the process of innovation.

- Farmers should operate as a network. Other stakeholders may join the network as well.

- Energy is an important criteria for selection: the network should show enthusiasm and willingness to invest time and, if necessary, money in the process.

- Technicians are acting as facilitators. They can speak the technical language of the network members and share their passion for the subject matter.

- Innovative networks require a free actor: someone who has the overview, the position and the capacity do what appears to be necessary to keep the network healthy.

- In the FAN approach such a free actor can be provided on a temporary basis by means of a knowledge worker. If the network is to continue, one of its members should take on this role.

- Free actors should be embedded in a structure for reflection and support. Although the work can be very satisfactory, at times it is also hard and bothersome. Then it is important to regain energy with sparring partners, and to reflect on ways to overcome the point of trouble any network encounters from time to time.

- The work of free actors requires a different set of tools from what is usual in project management. Instead of controlling the process, free actors have to navigate in unknown areas. These tools should help to recognise different network situations and offer options for intervention.

- The ecological view on knowledge, focussing on energy, connection and responsive capacity, offers a useful theoretical basis for the approach.

\section{Contribution to innovations}

If we define an innovation as a new practice that has become widely accepted, it can be questioned what the networks have contributed to this end. Most networks have made progress, but innovations according to the definition as widely accepted new practices cannot be recorded. It would not be very 
realistic to expect such innovations after only one year of work of a handful of entrepreneurs. In the language of the Spiral of Innovations we observe that the activities in the networks were mostly concentrated in the stages of inspiration, planning and development, while lesser networks progressed into the stages of implementation, dissemination and the embedding. In our opinion this contribution is nevertheless significant, since these early stages of the innovation process have been hard to address until present.

The programme enabled farmers to make connections with each other as well as other stakeholders, which probably would not have been made without a free actor who had relatively easy access to them because of his position within the knowledge system. Furthermore, the programme enabled the networks to share their experiences and results with others, through assistance in publications and the website. Lastly, the programme inspired numerous people to start their own initiative.

In former times the Dutch agricultural knowledge system had a world wide reputation for its innovative capacity with its short lines between farmers, industry, researchers and policy makers. The introduction of the knowledge market in the 90ties of the last century has changed the role of knowledge workers, especially of the intermediaries who used to be part of the government extension system and had to go commercial. This has left a vacancy in the system (Klerkx 2008). The FAN approach is an effort to fill this gap. There are always good initiatives, but most of them have no chance because of the many hurdles to overcome before they get support from investors or public funds. This is where the FAN approach has made its contribution.

\section{Challenges for the near future}

There are several issues that deserve attention in the time to come. One would like to see more networks being successful at the implementation stage and further. It can be questioned if this is only a matter of time. If so, the approach should be applied for projects taking longer than one year. It could also presumed that at the implementation stage other competences are required than can be expected from the subject matter specialists who have worked in the programme. Dealing with conflicts of interests at institutional levels is possibly demanding different skills.

Furthermore it would be interesting to investigate what the tools, that have been used in this programme, could contribute to such complicated and oftentimes tense processes.

An important question that remains to be answered is who takes responsibility for the role of the free actor after the experimental programme has ended. The programme results suggest that it is worthwhile to invest in this role, when it cannot be expected that individual farmers pay for it themselves. Should government keep on providing funds for it on a regular basis, or could the costs be shared with collective money from interest groups such as farmers organisations?

The programme as worked with hired subject matter specialists as facilitators and experts, while the farmers and other members joined the network on voluntary basis. The approach does not prescribe that only knowledge workers can act as free actor. Some entrepreneurs are very professional and skilful as well. It is well conceivable to use collective funds for a free actor approach to compensate them for an active role in their network.

The last challenge to be mentioned here is to build up a network of networkers who take time to reflect on their experiences working as free actors in networks. In The Netherlands we are working on such a network, including a training facility, as a follow up for the reflective structure for facilitators that was part of the programme. This network is open for international partners to join.

\section{International relevance}

Is the FAN approach only applicable under Dutch circumstances, which would be 'luxurious' as some foreign observers suggest, because of its rich tradition of cooperation minded farmers? We don't think so. The ecological view on knowledge and networks is not something to implement in a well organised society, but a way to understand what is happening between people, leading to answers on questions that cannot be solved in other rationalities. The mechanisms behind the way networks function are believed to be universal, although different cultures and historical backgrounds pose specific blockages to overcome. The power of people finding their way to join forces and becoming enthusiastic is definitely not typical Dutch. 
The problems that are related to the dominant paradigm of the knowledge market are felt internationally as well. It has led to an accumulation of planning and control mechanisms, creating a heavy administrative burden to all actors involved and leaving little room for creativity and innovativeness. We believe that creating space, instead of scoring on performance indicators, is highly relevant for processes of change, not only in The Netherlands. However, it not only requires a new generation of tools, as what we have been working on in the experiment, but also a change of mind: from controlling the process into dancing with life, creating space for the unknown, being confident that the result will be better than one could have thought of in advance when one succeeds in making essential connections. The reward is high: for those who dare to give up control, learning can turn into passion and the game of positioning can evolve into love.

\section{References}

Capra, F. (1996): The Web of Life: a New Synthesis on the Matter of Mind. London: HarperCollins. Kleiner, A, Roth, G (1997): Learning History. How to make your experience your company's best teacher. Harvard Business Review, Sept. 1997.

Klerkx, L.W.A. (2008): Matching demand and supply in the Dutch Agricultural knowledge infrastructure. Dissertation Wageningen University.

Maturana, H., Varela, F. (1987, 1992 revised edition): The Tree of Knowledge. The Biological Roots of Human Understanding. Boston: Shambhala.

Nonaka, I., Takeuchi, H. (1995): The Knowledge-Creating Company: How Japanese companies create the dynamics of innovation. New York, Oxford University Press,.

Poorthuis, A.M., Bijl, C. van der (2006): "Van netwerkanalyse naar organisatieroutine" [from network analysis to organisational routine]. In: Poorthuis, A.M. (red) (2006): De kracht van netwerkbenadering. [The power of network approaches]. Assen: Van Gorcum.

Röling, N.G., Wagemakers, M.A.E. (Eds)(1998): Facilitating Sustainable Agriculture: Participatory learning and adaptive management in times of environmental uncertainty. Cambridge: Cambridge University Press.

Röling, N.G., Hounkonnou, D, Offei, S.K., Toussou, R., Huis, A. van ((2004): Linking science and farmers' innovative capacity: diagnostic studies from Ghana and Benin. NAJS (52) 2004, p 211 Wielinga, H.E. (2001): Netwerken als levend weefsel. Een studie naar kennis, leiderschap en de rol van de overheid in de Nederlandse landbouw sinds 1945. [Networks as Living Tissue. A Study on Knowledge, Leadership and the Role of Government in Dutch Agriculture since 1945], PhD Thesis Wageningen University. Uilenreef Publisher, 's Hertogenbosch.

Wielinga, H.E. (2004): The Response-Ability of Networks: Healthy and Sick Agricultural Knowledge Networks in the Netherlands. In: Christovão (ed) 2004: European Farming and Society in Search of a New Social Contract - Learning to Manage Change. Proceedings of the Sixth European IFSA Symposium, Volume 2 p.483 - 496. UTAD, Vila Real.

Wielinga, H.E. (2006): Intermediate Roles in Privatized Extension Systems: The Dutch Case. In: Langeveld, H, Röling, N.G. eds (2006): Changing European Farming Systems for a Better Future. pp381-385. Proceedings of the European IFSA Conference, Wageningen 2006. Wageningen Academic Publishers.

Wielinga, H.E. (2007): Networking with free actors: the FAN approach, Dutch experiences with 120 networks in animal husbandry. In: Slavik, M., Zakova, P. (Eds) (2007): Supporting Viable Rural Communities. Proceedings of the $18^{\text {th }}$ ESEE conference, Prague. Czech University of Life Sciences. Prague.

Wielinga, H.E. et al (2008): Networks with free actors, encouraging sustainable innovations in animal husbandry by using the FAN approach (134p, in print), Wageningen UR, Wageningen. 